\title{
CONTROLE DE CUSTOS NA PRODUÇÃO DO GADO DE CORTE: UM ESTUDO DE CASO EM UMA PROPRIEDADE RURAL DE SANTA CATARINA
}

\author{
Daniela Di Domenico ${ }^{1}$ \\ Cristian Baú Dal Magro ${ }^{2}$ \\ Antonio Zanin ${ }^{3}$ \\ Raphael Martini ${ }^{4}$
}

\begin{abstract}
RESUMO
O estudo teve como objetivo relacionar e analisar os custos na atividade da pecuária de corte em uma propriedade rural do Oeste Catarinense. A pesquisa se classifica quanto aos objetivos como exploratória, quanto aos procedimentos como documental, e quanto a abordagem do problema de caráter quantitativo. Os controles da contabilidade rural e da contabilidade de custos, quando implantados têm como meta auxiliar o empresário rural na tomada de decisão, obtendo um real controle de suas entradas, gastos e custos, envolvidos na atividade da pecuária, tendo, assim, maior controle e gestão da atividade. Os resultados apontaram que com o uso dos controles fornecidos pela contabilidade rural e contabilidade de custos, é possível que o proprietário rural obtenha a real situação econômica e financeira da propriedade, e seus respectivos custos e despesas, os quais irão contribuir com a tomada de decisão em busca de melhor lucratividade.
\end{abstract}

Palavras-chaves: atividade pecuária, contabilidade rural, controle de custos.

\section{COST CONTROL IN THE PRODUCTION OF BEEF CATTLE: CASE STUDY ON A FARM IN SANTA CATARINA}

\footnotetext{
ABSTRACT

The study aimed to relate and analyze the costs in beef cattle activity on a farm west of Santa Catarina. The survey ranks as the goals as exploratory, as the procedures as a documentary, and as the approach of the quantitative character problem. The

${ }^{1}$ Mestre em Ciências Contábeis pela Universidade Regional de Blumenau - FURB. Professora do Curso de Ciências Contábeis da Universidade Comunitária da Região de Chapecó - UNOCHAPECÓ. Email: didomenico@unochapeco.edu.br.

${ }^{2}$ Mestre em Ciências Contábeis pela Universidade Regional de Blumenau - FURB. Doutorando em Ciências Contábeis e Administração pela Universidade Regional de Blumenau - FURB. Email: cristianbaumagro@gmail.com.

${ }^{3}$ Doutor em Engenharia de Produção pela Universidade Federal do Rio Grande do Sul - UFRGS.

Coordenador e Professor do Mestrado Acadêmico em Ciências Contábeis e Administração da Universidade

Comunitária Regional de Chapecó - UNOCHAPECÓ. Email: zanin@unochapeco.edu.br.

${ }^{4}$ Graduado em Ciências Contábeis pela Universidade Comunitária da Região de Chapecó -

UNOCHAPECÓ. Email: raphaelmartini@gmail.com
} 
controls of rural accounting and cost accounting, when implanted aim to assist rural entrepreneurs in decision making, getting a real control of their inputs, expenses and costs involved in livestock activity, and thus have greater control and management activity. The results showed that using the controls provided by rural accounting and cost accounting, it is possible that the landowner get the real economic and financial situation of the property, and their respective costs and expenses, which will contribute to the decision-making in search of better profitability.

Key words: cost accounting, livestock activity, rural accounting.

\section{INTRODUÇÃO}

A contabilidade é uma ferramenta que auxilia no controle do desempenho econômico, financeiro e patrimonial, controle dos custos e análise da rentabilidade, além de um importante papel como ferramenta de apoio na gestão da propriedade rural. É por meio das informações fornecidas pela contabilidade que o produtor rural planeja, controla, toma decisões e gerencia os custos e sistemas de produção.

Considerando como amostra uma propriedade rural do oeste catarinense, o presente trabalho procura responder a seguinte questão: quais são os custos incorridos na produção do gado de corte em uma propriedade rural do Oeste Catarinense? Para responder a inquietação exposta, o objetivo geral da pesquisa é identificar os custos incorridos na produção do gado de corte em uma propriedade rural do Oeste Catarinense.

A pesquisa justifica-se pelo fato de que o estudo dos custos rurais é um assunto relevante para indicar as atividades que devem circunstancialmente ser ou não incentivadas, tendo em vistas que os valores de mercado dos fatores de produção se alteram constantemente. Também é justificado que poucos produtores rurais fazem anotações contábeis de forma sistemática, e portanto, não conseguem mensurar de maneira adequada a realidade econômica e financeira do negócio.

\section{CONTABILIDADE RURAL APLICADA NA GESTÃO DA PROPRIEDADE}

As empresas rurais, de pequeno e médio porte, são, em sua grande parte administradas por familiares, em que o patriarca é chefe da família e administrador da propriedade em simultâneo. Uma das grandes dificuldades encontradas nesse meio é o pouco conhecimento das ferramentas contábeis que contribuem para o controle eficiente das atividades.

Calderelli (1997, p. 180) define que a Contabilidade Rural é "aquela que tem suas normas baseadas na orientação, controle e registro dos atos e fatos ocorridos e praticados por uma empresa cujo objeto de comércio ou indústria seja agricultura ou pecuária". Assim, é através dos registros contábeis que o produtor rural obtém informações precisas para desempenhar um controle de gestão eficiente das atividades.

Para Crepaldi (2011, p. 81), "a contabilidade rural é um dos principais sistemas de controle de informação das empresas rurais". É por meio dela que se podem analisar os relatórios contábeis para verificar a real situação econômica, financeira e patrimonial das entidades.

Hofer et al. (2006) comentam que a contabilidade tem a importância de auxiliar empresários na tomada de decisões e na elaboração das estratégias.

Contudo, a empresa precisa de uma administração eficiente, que conheça todos os aspectos relacionados ao negócio e ao capital. Além disso, o empresário 
deve se especializar continuamente, aumentando seu conhecimento e visando à modernização do sistema agropecuário. Assim, o empresário terá uma administração mais ampla e abrangente de desempenhos físicos e financeiros.

Desse modo, Borilli et al. (2005) corroboram salientando que a obtenção de sucesso por parte do empresário rural está condicionada a uma administração eficiente, e isso requer conhecimento do negócio, do capital, da especialização e da modernização da agropecuária. É justamente nesses aspectos que a empresa rural apresenta carências e prejudica todo $o$ processo de desenvolvimento e modernização do setor.

O sucesso da empresa rural não consiste somente na aplicação de técnicas modernas para o aumento da produtividade, mas também é necessário o controle dos custos da produção. É preciso gerenciar a produtividade para alcançar o resultado desejado e continuar prosperando com lucros significativos (DAL MAGRO et al., 2013). Destaca-se, dessa forma, a importância da Contabilidade Rural, voltada principalmente para a gestão de custos nas mais diversas atividades rurais (CALLADO; ALMEIDA, 2005).

De acordo com Marion (2012), a contabilidade pode ser estudada de maneira ampla, genérica, denominada de contabilidade geral ou financeira. Mas, quando é direcionada a um segmento específico, deve estar em consonância com a atividade daquele ramo. O exemplo disso é a contabilidade rural aplicada às empresas que possuem atividades agrícolas.

Para tanto, a fim de que a contabilidade rural seja aplicada de forma correta na atividade agrícola, é preciso separar a cultura temporária e a permanente. Crepaldi (2011, p. 106) salienta que a cultura temporária é "aquela sujeita ao replantio após a colheita, possuindo período de vida muito curto entre o plantio e a colheita, como por exemplo, os cultivos de milho, legumes, soja, etc". Essa cultura, também conhecida como cultura anual, pode ser replantada após a colheita, possuindo um ciclo de vida curtíssimo. O produtor trata a terra e pode cultivar o mesmo produto, e também outros produtos que desejar.

Por outro lado, Marion (2012, p. 18) menciona que a cultura permanente é "aquela que permanece vinculada ao solo e proporciona mais de uma colheita ou produção. Normalmente, atribui-se a cultura permanente uma duração mínima de quatro anos". Na cultura permanente é possível extrair mais de uma colheita ou produção. Ela não está sujeita ao replantio. Exemplo: café, laranja, macieira, etc.

Recentemente, a contabilidade sofreu algumas alterações que também impactaram na aplicação e mensuração dos aspectos relacionados à contabilidade rural. A implantação das normas internacionais de contabilidade pelo International Accounting Standard Board (IASB) e reguladas pelo Comitê de Pronunciamentos Contábeis (CPC) no Brasil, fez surgir o CPC 29, relacionado aos Ativos Biológicos e Produtos Agrícolas, resultando em alterações no reconhecimento de ativos, avaliações de custos, dentre outras. Conforme Marion (2012, p. 33), o ativo biológico é "tudo aquilo que nasce cresce, e morre, desde as culturas temporárias e permanentes até mesmo animais, rebanhos de reprodução e corte".

De acordo com o CPC 29, os ativos biológicos são todos os produtos que não sofreram nenhum tipo de alteração. A partir do momento em que o produto sofre alguma alteração, passa a ser um produto agrícola. Quando o produto passa por alguma fase de processamento e/ou beneficiamento é chamado de produto resultado do processamento após a colheita. Assim, como exemplo, a soja em seu período de crescimento é um ativo biológico, quando colhida passa a ser um produto agrícola, e quando beneficiada pode tornar-se óleo de soja, e passa a ser chamada de produto resultante do processamento. 
Segundo Marion (2012), a grande mudança incrementada pelo CPC 29 foi com relação a avaliação dos ativos biológicos: antes eram contabilizados pelo custo e agora são contabilizados pelo valor justo menos as despesas para colocar o ativo à venda, necessitando neste enfoque, diferenciar o valor contábil de valor justo.

O valor contábil, de acordo com CPC 29, é o montante pelo qual um ativo é reconhecido no balanço. Por outro lado, o valor justo é o valor pelo qual um ativo pode ser negociado, ou um passivo liquidado, entre partes interessadas, conhecedoras do negócio e independentes entre si, com a ausência de fatores que pressionem para a liquidação da transação ou que caracterizem uma transação compulsória.

O CPC 29 ressalta que, caso haja perda ou ganho com esses ativos, em razão da variação de mercado, deve-se evidenciar no patrimônio da empresa, subsidiando ao empresário a melhor tomada de decisão que seja cabível para o momento perpassado pela organização. Por fim, Costa et al. (2004) ressaltam sobre o fato de a contabilidade rural não abranger apenas o setor agrícola, mas também as atividades zootécnicas e agroindustriais. Contemplam que as peculiaridades pertinentes às atividades agrícolas, zootécnicas e agroindustriais são diferenciadas da contabilidade aplicável a outros setores. Para tanto, o capítulo a seguir aborda sobre os fatores realizados na atividade da pecuária que é o foco deste estudo.

\subsection{Atividade pecuária}

A atividade pecuária influencia de forma direta na economia do Brasil que também é um grande consumidor de carne. As regiões que mais produzem gado de corte são, Sudeste, Centro Oeste e o Sul. Segundo Marion (2012, p.6), pecuária é a "arte de criar e tratar o gado". A pecuária cuida de animais geralmente criados no campo para abate, consumo doméstico, serviços na lavoura, reprodução, leite e para fins industriais e/ ou comerciais.

Conforme Marion (2012), na atividade da pecuária não se tem o encerramento de acordo com o exercício social (janeiro a dezembro). Assim, o encerramento do exercício deve levar em consideração o nascimento ou desmame dos animais.

Segundo Crepaldi (2011), o rebanho é classificado de acordo com sua categoria, sendo o recém nascido considerado bezerro e, após o desmame, é chamado de novilho. Além dessa classificação, entre as diferentes etapas do rebanho, as fases também são dividas.

Consoante Marion (2012) há três fases distintas na atividade do gado de corte. A primeira é na produção de bezerros que são chamados de cria; a segunda é a produção e a venda do novilho gordo que são chamados de recria; e, por fim, a terceira é a partir do novilho magro adquirido. A produção e a venda do novilho gordo são chamados de engorda.

Marion (2012) destaca que o gado de corte é destinado à produção de carne, podendo ser alocado em currais ou piquetes, em análises dos diferentes tipos de sistemas utilizados, como o sistema extensivo e semiextensivo. Percebe-se que, através de um sistema extensivo, o gado ganha mais peso, pois é criado livremente e não tem a forma controlada como nos cochos, que é considerado o sistema semiextensivo.

Porém, quando se trata de criação para a comercialização, é de fundamental importância que o empresário rural e/ou agricultor mantenha certo controle de seus animais, sabendo, assim, quais animais estão prontos para o abate e quais ainda serão preparados para a venda. Nesse contexto, a contabilidade poderá servir como ferramenta gerencial para a tomada de decisão. 
Por fim, é por meio do controle de custos que o empresário saberá qual é a rentabilidade das suas atividades. Dessa forma, é necessário um bom controle e, nesse aspecto, é fundamental a utilização das ferramentas da contabilidade de custos.

\subsection{Contabilidade de custos na atividade pecuária}

A contabilidade de custos é necessária para as empresas que buscam manter sua continuidade e crescimento no mercado, pois é uma ferramenta que procura apresentar informações específicas para cada caso. Além de contribuir para o controle e gerenciamento de acordo com as necessidades do usuário, proporciona um diferencial competitivo em relação aos concorrentes.

O controle e o acompanhamento dos custos permitem que os empresários rurais visualizem quais são os maiores custos e ou despesas que mais impactam na sua atividade. Assim, um bom controle possibilita monitorar as metas de cada atividade de produção e é uma ferramenta de gestão que permite análise econômica mais detalhada e precisa das atividades produtivas (EMBRAPA, 2013).

Bruni e Famá (2011, p. 22) definem a contabilidade de custos "como o processo ordenado de usar os princípios da contabilidade geral para registrar os custos de operações de um negócio". Dessa maneira, com as informações geradas pelos dados operacionais é possível estabelecer os custos de produção.

Os custos são fatores determinantes para correta tomada de decisões, as quais demonstram informações e ideias relevantes para serem aplicadas em estratégias de mercado, podendo se utilizar da contabilidade de custos e fazer adaptações necessárias de acordo com as necessidades individuais de cada entidade. Por isso o empresário rural precisa estar a par de como funciona cada atividade dentro de sua empresa, tendo assim maior controle de custos (SANTOS; MARION; SEGATTI, 2002).

Para Vanderbeck e Nagy (2001), é comum encontrar, nos diversos ramos empresariais, um sistema de contabilidade de custos que demonstre os custos incorridos e apresente onde as despesas foram usadas. As informações contábeis exigem um sistema de informações que é projetado para a acumulação de dados detalhados dos custos relacionados ao processo de produção.

Segundo Padoveze (2006, p. 4), custo pode ser definido "como sendo a mensuração econômica dos recursos (produtos, serviços e direitos) adquiridos para a obtenção e a venda de produtos e serviços da empresa". O custo de um produto ou serviço nada mais é que o valor pago por ele.

Para Bruni e Famá (2011, p. 23), as despesas "correspondem à bem ou serviço consumido direta ou indiretamente para a obtenção de receita. Não estão associadas à produção de um produto ou serviço". A diferença entre custo e despesa é que o custo é todo o valor agregado ao produto final, é tudo aquilo que foi utilizado para a obtenção do resultado final, é agregado ao produto da empresa, enquanto que a despesa não pode ser agregada. Ela faz parte do processo funcional da empresa.

Os custos e as despesas se dividem em fixos ou variáveis. Para Neves e Viceconti (2000, p.18), custos fixos "são aqueles cujos valores são os mesmos em qualquer que seja o volume de produção da empresa". Exemplo: energia elétrica sem possuir medidor em cada ponto específico. Por outro lado, Neves e Viceconti (2000, p.18) expõem que os custos variáveis "são aqueles cujos valores se alteram em função do volume de produção". Exemplo: materiais consumidos, hora/máquina trabalhada. 
As despesas também se dividem em fixas e variáveis. Segundo Bruni e Famá (2011, p. 32), despesas fixas "não variam em função do volume de vendas" e despesas variáveis "variam de acordo com as vendas". O exemplo de despesas fixas é o aluguel e seguros; o exemplo de despesas variáveis é comissão sobre vendas e gastos com fretes.

Os custos também podem ser divididos em direto e/ou indireto. Para Bornia (2010, p.21), custos diretos "são aqueles facilmente relacionados com as unidades de alocação de custos". Exemplo: matéria prima e mão de obra direta. Para Bornia (2010, p.21), os custos indiretos "não podem ser facilmente atribuídos às unidades, necessitando de alocações para isso". Exemplo: mão de obra indireta.

Desse modo, com a aplicação dos conceitos estabelecidos pela contabilidade de custos, o empresário rural terá conhecimento mais abrangente sobre os custos incorridos no processo de produção, bem como a exata visão dos gastos que deverão ser incluídos no preço de venda do gado. Assim, com a aplicação do controle de custos, o proprietário rural saberá exatamente quais são os gastos para a produção de suas atividades.

Segundo Zanin et al. (2010, p. 71), "a gestão de custos é fundamental para as organizações, como forma de identificar e gerenciar os gastos necessários para produzir cada unidade do determinado produto [...]". O controle de custeio de uma organização tem, entre as finalidades, analisar a atividade para melhor gerenciamento da produtividade, consequentemente aumento da rentabilidade e também serve para avaliar os estoques. Entre os sistemas de custeio mais utilizados tem-se o custeio por absorção.

O método do custo na atividade pecuária assemelha-se ao de uma empresa industrial, ou seja, são apropriados ao rebanho todos os custos ocorridos e a eles pertencentes, fazendo a distribuição do custo do rebanho entre as cabeças de gado existentes. Para Neves e Viceconti (2000), o custeio por absorção é o processo que apura os custos por meio de rateio, ou seja, todos os elementos envolvidos, sejam eles custos fixos ou variáveis, para cada fase da produção. A parcela de custo é atribuída ao produto conforme for utilizado no processo de produção.

\section{METODOLOGIA DA PESQUISA}

O estudo é caracterizado quanto aos objetivos, como uma pesquisa exploratória. Foram utilizadas diversas técnicas de coleta de dados para o desenvolvimento da pesquisa foi utilizado entrevista não-estruturada. E quanto a abordagem do problema foi de caráter qualitativo. Foi realizado um acompanhamento na produção do gado de corte durante o período de janeiro a julho de 2012. Com os dados obtidos foi possível levantar os custos da atividade para posteriormente montar o demonstrativo de resultado e o balanço patrimonial da propriedade.

A pesquisa foi realizada em uma propriedade rural no interior de um município do oeste catarinense, a qual desenvolve a atividade de gado de corte. Possui uma área de 172 hectares (ha), sendo utilizados 130 ha para piquete, uma cocheira de confinamento $10 \mathrm{~m} \times 1,5 \mathrm{~m}$ (parte de cocho), $25 \mathrm{~m} \times 15 \mathrm{~m}$ para colocar o gado à noite, uma área de 10 ha para plantar milho, o qual é utilizado para silagem $e$ grão. Possui, ainda, uma casa para o chacareiro e sua família, um galpão onde é armazenada ração e medicamentos para os animais, um trator, uma máquina de veneno, roçadeira, máquina de silagem e plantadeira. O restante da área são potreiros, mata e capoeirão. 
As movimentações econômicas, financeiras e patrimoniais e os custos serviram como base para elaboração da Demonstração do Resultado do Exercício do período compreendido pelo estudo. Utilizando das informações do Balanço Patrimonial Inicial e da Demonstração do Resultado do Exercício, foi elaborado o Balanço Patrimonial do Encerramento do exercício.

Após esses procedimentos adotados, foram levantadas sugestões, orientações para que a empresa rural possa crescer e obter maior controle. Também se elaborou o controle por meio do real custo da atividade, a fim de que o produtor consiga chegar a um maior controle no seu processo.

\section{ANÁLISE E INTERPRETAÇÃO DOS RESULTADOS}

Para atingir o objetivo do presente estudo, os dados coletados na propriedade foram demonstrados e analisados na seguinte forma: apresentação do levantamento dos custos de produção, engorda do boi, apresentação da Demonstração do Resultado do Exercício e apresentação do Balanço Patrimonial. Pelo fato de a propriedade não possuir um sistema de controle dos custos e das despesas, foi analisada a atividade para levantar os gastos incorridos na realização da atividade da pecuária.

Com a elaboração de um controle de custos confiável, o produtor rural terá condições de tomar suas decisões com bases seguras e concretas. Assim, poderá visualizar todos os gastos incorridos em determinada atividade, a fim de verificar possíveis custos ou despesas desnecessárias, contribuindo para formação do preço final de seu produto.

Dessa forma, inicialmente foi utilizado o custo histórico para alocação de custo ao bovino e, posteriormente, atribuído o valor justo para possíveis ajustes de valores. Os valores utilizados para os cálculos foram os preços de mercado da época, correspondentes ao período de setembro de 2010, época em que ocorreu o primeiro plantio na propriedade em estudo. Os insumos, mão de obra e diesel foram corrigidos aos valores da época e eles integraram o custo histórico do estoque.

A fazenda utiliza-se de diversos procedimentos para as diferentes etapas da engorda. Para tanto, todos os custos alocados foram distribuídos na fase específica do bovino.

A primeira etapa do estudo foi a análise no plantio do milho que serve para a alimentação na engorda dos bovinos. Dessa forma, o milho, quando colhido, é utilizado na alimentação em forma de grão ou é transformado em silagem. Destacase que as depreciações dos equipamentos utilizados no plantio e na silagem foram alocadas ao custo conforme o tempo de utilização para a cultura.

\subsection{Cálculo do custo da produção de milho}

A propriedade rural possui uma área de 10 hectares que utilizada especificamente para o plantio da cultura (milho). A colheita da cultura (milho) é utilizada para a engorda dos bovinos de duas maneiras: $80 \%$ da colheita é transformado em silagem e $20 \%$ é utilizado como ração bovina em forma de grão na etapa do confinamento. A tabela 1 demonstra o cálculo dos insumos utilizados no plantio e na manutenção da cultura (milho). 
Tabela 1 - Cálculo dos insumos utilizados no plantio e na manutenção da cultural (milho).

\begin{tabular}{|c|c|c|c|c|}
\hline Mês & & Quantidade & Valor Unitário (R\$) & Total (R\$) \\
\hline \multirow[t]{5}{*}{$1^{\circ}$} & Adubo & 50 sacas & 47,00 & $2.350,00$ \\
\hline & Herbicida & 25 litros & 16,48 & 412,00 \\
\hline & Inseticida & 2,5 litros & 8,83 & 22,08 \\
\hline & Semente & 10 sacas & 275,00 & $2.750,00$ \\
\hline & Uréia & 50 sacas & 48,00 & $2.400,00$ \\
\hline \multirow[t]{2}{*}{$2^{\circ}$} & Inseticida & 2,5 litros & 8,83 & 22,08 \\
\hline & Uréia & 25 sacas & 48,00 & $1.200,00$ \\
\hline 3 은 & & - & - & - \\
\hline \multirow[t]{2}{*}{$4^{\circ}$} & Inseticida & 2,5 litros & 8,83 & 22,08 \\
\hline & Uréia & 25 sacas & 48,00 & $1.200,00$ \\
\hline Total & & & & $10.378,24$ \\
\hline
\end{tabular}

Fonte: dados da pesquisa.

Observa-se, na tabela 1, o cálculo dos custos dos insumos utilizados no plantio e na manutenção da cultural (milho) que perdurou por um período de 4 meses. Assim, no $1^{\circ}$ mês ocorre o plantio da cultura com o uso de adubo, herbicida, inseticida, semente e ureia, totalizando um custo de $R \$ 7.934,08$. No $2^{\circ}$ mês, foi utilizado inseticida para combater os insetos e ureia para auxiliar no crescimento, totalizando um custo de $\mathrm{R} \$ 1.222,08$. No $3^{\circ}$ mês, não foi aplicado nenhum insumo para manutenção da cultura do milho. Por fim, no $4^{\circ}$ mês, foi utilizado inseticida para combater os insetos e ureia para auxiliar no crescimento do milho, totalizando um custo de $R \$ 1.222,08$. A tabela 2 mostra o cálculo de hora máquina utilizada no plantio e na manutenção da cultura (milho).

Tabela 2 - Cálculo hora máquina utilizada no plantio e na manutenção da cultura (milho).

\begin{tabular}{ccccccr}
\hline Mês & Horas & $\begin{array}{c}\text { Consu } \\
\mathbf{m o} \\
(\mathbf{I} / \mathbf{h})\end{array}$ & $\begin{array}{c}\text { Valor do } \\
\text { diesel (R\$) }\end{array}$ & Dias & Depreciação & Total (R\$) \\
\hline $\mathbf{1}^{\mathbf{0}}$ & 12 & 5 & 1,53 & 2 & 526,32 & 709,92 \\
$\mathbf{2}^{\mathbf{0}}$ & 6 & 5 & 1,53 & 2 & 263,16 & 354,96 \\
$\mathbf{3}^{\circ}$ & - & - & - & - & - & - \\
$\mathbf{4}^{\mathbf{0}}$ & 6 & 5 & 1,53 & 2 & 263,16 & 354,96 \\
Total & & & & & & \\
\hline
\end{tabular}

Fonte: dados da pesquisa.

A tabela 2 demonstra que os custos com hora máquina foram separados durante o período de plantio e manutenção da cultura (milho), ou seja, durante 4 (quatro) meses. Para o plantio e manutenção da colheita foi utilizado um trator avaliado no valor de $\mathrm{R} \$ 50.000,00$ (cinquenta mil reais) e depreciado em $10 \%$ a.a, ou seja, com uma depreciação anual de $R \$ 5.000,00$. Foi verificado que, em média, o trator trabalha 228 horas/ano, sendo assim, os custos com depreciação foram rateados proporcionalmente ao tempo de uso na cultura (milho). 
Dessa forma, verifica-se que, no $1^{\circ}$ mês, foram utilizadas 12 (doze) horas de trator ao dia, num total de 2 (dois) dias e que o trator consome em média 5 litros/hora, sendo que o valor do diesel é de $R \$ 1,53$ o litro, totalizando um custo de $\mathrm{R} \$ 709,92$ com depreciação e combustível.

No $2^{\circ}$ mês, foram utilizadas 6 (seis) horas de trator ao dia, num período de 2 (dois) dias, com o mesmo consumo de combustível. O custo total foi de $\mathrm{R} \$ 354,96$ com depreciação e combustível. No $3^{\circ}$ mês não foram incorridos custos e, por fim, no $4^{\circ}$ mês, incorreram os mesmos custos do $2^{\circ}$ mês. Desse modo, o total de custos apresentados no cálculo hora máquina utilizada no plantio e na manutenção da cultura (milho) foi de $\mathrm{R} \$ 1.419,84$ que compreendem a depreciação e o consumo de combustível do trator.

O empresário rural emprega um funcionário que recebe o valor fixo de $\mathrm{R} \$ 1.200,00 / \mathrm{mês}$. Dessa forma, o salário do empregado precisa ser rateado proporcionalmente ao tempo trabalhado na atividade de produção do gado de corte e na atividade da cultural (milho). Para tanto, a tabela 3 mostra o cálculo da mão de obra utilizada no plantio e na manutenção da cultural (milho).

Tabela 3 - Cálculo da mão de obra utilizada no plantio e na manutenção da cultural (milho).

\begin{tabular}{rccc}
\hline Mês & Salário Fixo & $\begin{array}{c}\text { Tempo de dedicação na } \\
\text { atividade de plantio e } \\
\text { manutenção da cultura (milho) }\end{array}$ & Total \\
\hline $\mathbf{1}^{\mathbf{0}}$ & $1.200,00$ & $30 \%$ & 360,00 \\
$\mathbf{2}^{\mathbf{0}}$ & $1.200,00$ & $15 \%$ & 180,00 \\
$\mathbf{3}^{\mathbf{o}}$ & $1.200,00$ & $10 \%$ & 120,00 \\
$\mathbf{4}^{\mathbf{0}}$ & $1.200,00$ & $15 \%$ & 180,00 \\
\hline Total & & & $\mathbf{8 4 0 , 0 0}$ \\
\hline
\end{tabular}

Fonte: dados da pesquisa.

Verifica-se, na tabela 3 , que, no $1^{\circ}$ mês de plantio da cultura (milho), o funcionário trabalhou $30 \%$ do seu tempo nessa atividade. No $2^{\circ}$ mês, o funcionário trabalhou $15 \%$ do seu tempo na manutenção da cultura (milho). No $3^{\circ}$ mês, o funcionário trabalhou $10 \%$ do seu tempo e, por fim, no $4^{\circ}$ mês, trabalhou $15 \%$ do seu tempo na manutenção da cultura, totalizando um custo de mão de obra para plantio e manutenção da cultura (milho) no valor de $R \$ 840,00$. A tabela 4 demonstra 0 custo total de plantio e manutenção da cultura milho, bem como o rateio para 0 produto em grão e silagem.

Tabela 4 - Custo total do plantio e manutenção da cultural (milho).

\begin{tabular}{|c|c|c|c|c|c|}
\hline \multirow{2}{*}{$\begin{array}{c}\text { Custo } \\
\text { insumos, } \\
\mathbf{R} \$\end{array}$} & \multirow{2}{*}{$\begin{array}{l}\text { Custo da } \\
\text { hora } \\
\text { máquina, } \\
\text { R\$ }\end{array}$} & \multirow{2}{*}{$\begin{array}{l}\text { Custo } \\
\text { com } \\
\text { mão de } \\
\text { obra, R\$ }\end{array}$} & \multirow[t]{2}{*}{$\begin{array}{c}\text { Custo } \\
\text { total, } \mathrm{R} \$\end{array}$} & \multicolumn{2}{|c|}{$\begin{array}{l}\text { Rateio do custo total } \\
\text { plantio e manutenção da } \\
\text { cultura (milho), R\$ }\end{array}$} \\
\hline & & & & Grão 20\% & Silagem $80 \%$ \\
\hline $10.378,24$ & $1.419,84$ & 840,00 & $12.638,08$ & $2.527,62$ & $10.110,46$ \\
\hline
\end{tabular}

Fonte: dados da pesquisa.

Verifica-se, na tabela 4, que o custo total do plantio e manutenção da cultura (milho) foi de $\mathrm{R} \$ 12.638,08$. O valor foi rateado em $20 \%$ para grão, totalizando um custo de $R \$ 2.527,62$ e rateado em $80 \%$ para a silagem, totalizando um custo de $\mathrm{R} \$ 10.110,46$. 
A partir do 5ำ mês, a cultura milho foi colhida e destinada para alimentação em forma de grãos e parte foi transformada em silagem para alimentação do gado de corte. Assim, para a separação dos custos com da colheita em grãos e em silagem, a propriedade utilizou os seguintes critérios: na colheita do milho em grão foi utilizada uma colheitadeira que é de propriedade de um vizinho.

O pagamento do empréstimo da colheitadeira foi acertado da seguinte forma: $10 \%$ da colheita em 2 hectares será destinado ao pagamento da locação. Assim, do total colhido nos 2 hectares, $90 \%$ se destinará ao estoque da propriedade rural. Destaca-se que os gastos com combustível correrão por conta do empresário rural e a depreciação da colheitadeira não incorporará os custos do gado de corte, cabendo ao locador da máquina destinar de forma adequada as despesas com depreciação. Por fim, o empresário rural não irá arcar com os custos de operador da máquina. A tabela 5 mostra o cálculo da hora máquina terceirizada para a colheita dos 2 hectares da cultural (milho) que será transformada em grão.

Tabela 5 - Cálculo da hora máquina terceirizada na colheita da cultura transformada em grão.

\begin{tabular}{cccccc}
\hline Máquina & Horas & Litros & Valor Diesel & Dias & Total \\
\hline Terceirizada & 8 & $5 \mathrm{l} / \mathrm{h}$ & $\mathrm{R} \$ 1,53$ & 2 & $\mathrm{R} \$ 122,40$ \\
\hline
\end{tabular}

Fonte: dados da pesquisa.

Verifica-se, na tabela 5, que foi utilizado um total de 16 horas para a colheita da cultura (milho) transformada em grão e o custo do combustível foi de $R \$ 5,00$ de litros/hora, totalizando um custo de $R \$ 122,40$.

Para a colheita dos 8 hectares da cultura (milho) que é transformada em silagem foi utilizado um trator da propriedade e um trator terceirizado. A depreciação utilizada será referente ao trator da propriedade, cabendo ao proprietário do trator terceirizado fazer seus devidos tratamentos. A tabela 6 mostra o cálculo da hora máquina na colheita da cultura transformada em silagem.

Tabela 6 - Cálculo da hora máquina na colheita da cultura transformada em silagem.

\begin{tabular}{lcccccc}
\hline \multicolumn{1}{c}{ Máquina } & Horas & Litros & $\begin{array}{c}\text { Valor } \\
\text { Diesel }\end{array}$ & Dias & $\begin{array}{c}\text { Deprecia- } \\
\text { ção }\end{array}$ & Total (R\$) \\
\hline Própria & 12 & $5 \mathrm{l} / \mathrm{h}$ & $\mathrm{R} \$ 1,53$ & 7 & $\mathrm{R} \$ 1.842,10$ & $2.484,70$ \\
Terceirizada & 5 & $5 \mathrm{l} / \mathrm{h}$ & $\mathrm{R} \$ 1,53$ & 7 & - & 267,75 \\
\hline
\end{tabular}

Fonte: dados da pesquisa.

Observa-se, na tabela 6 , que foram utilizadas 12 horas de trator da propriedade e 5 horas de trator terceirizado. Assim, o custo do trator da propriedade que incluiu combustível e depreciação foi de $R \$ 2.484,70$ e o custo do trator terceirizado que incluiu apenas o combustível foi de $\mathrm{R} \$ 267,75$.

Para a colheita e transformação do milho em grão e silagem foi utilizada mão de obra terceirizada a um custo de $R \$ 40,00$ /dia de trabalho. Na colheita do milho transformado em silagem foram utilizados três dias de mão de obra terceirizada e na colheita do milho transformado em grão não foi necessária a contratação de mão de obra terceirizada. A tabela 7 demonstra os custos de produção da silagem. 
Tabela 7 - Custos de produção da silagem.

\begin{tabular}{lr} 
Custo do plantio e manutenção & $\mathrm{R} \$ 10.110,46$ \\
Custo hora máquina da propriedade & $\mathrm{R} \$ 2.484,70$ \\
Custo hora máquina terceirizada & $\mathrm{R} \$ 267,75$ \\
Custo mão de obra da propriedade & $\mathrm{R} \$ 360,00$ \\
Custo mão de obra terceirizada & $\mathrm{R} \$ 120,00$ \\
$\quad$ Total & $\mathbf{R} \$ \mathbf{1 3 . 3 4 2 , 9 1}$ \\
Produção de silagem & $332.000 \mathrm{~kg}$ \\
Custo por kg produzido & $\mathrm{R} \$ 0,0402$ \\
\hline
\end{tabular}

Fonte: dados da pesquisa.

Verifica-se, na tabela 7, que, para o cálculo dos custos de produção da silagem, foi utilizado o custo do plantio e manutenção (tabela 4), o custo da hora máquina da propriedade e a terceirizada (tabela 6) e, por fim, o custo da mão de obra da propriedade e a terceirizada, totalizando um custo de produção da silagem no valor de $R \$ 13.342,91$. Por fim, a tabela 7 mostra que foram colhidos $332.000 \mathrm{~kg}$ de milho para silagem em 8 hectares. A tabela 8 demonstra os custos de produção de grãos.

Tabela 8 - Custos de produção de grãos.

\begin{tabular}{lr} 
Custo do plantio e manutenção & $\mathrm{R} \$ 2.527,62$ \\
Custo do combustível & $\mathrm{R} \$ 122,40$ \\
Total & $\mathbf{R} \mathbf{2 . 6 5 0 , 0 2}$ \\
Produção de grãos & $14.580 \mathrm{~kg}$ \\
Custo por kg produzido & $\mathrm{R} \$ 0,1818$ \\
\hline
\end{tabular}

Fonte: dados da pesquisa.

Observa-se, na tabela 8, que, para o cálculo dos custos de produção de grãos, foi utilizado o custo do plantio e manutenção (tabela 4) e o custo do combustível (tabela 5), totalizando um custo para produção de grãos no valor de $\mathrm{R} \$ 2.650,02$. Por fim, verifica-se que foram colhidos $14.580 \mathrm{Kg}$ de grãos em 2 hectares. Assim, dos $14.580 \mathrm{~kg}$ de grãos colhidos, $10 \%$ foi destinado ao pagamento da locação da máquina terceirizada, ou seja, $1.458 \mathrm{~kg}$ de grãos de milho.

O proprietário da colheitadeira vizinha retira do seu trabalho $1.620 \mathrm{~kg}$ de grãos de milho com o acordo firmado entre os proprietários. Portanto, o custo total é rateado com $90 \%$ da produção de grão de milho.

Além dos custos com grãos e silagem, é preciso levar em consideração os custos para plantio e manutenção da pastagem que também será utilizada para alimentação na engorda do gado o qual será comercializado. Pela dificuldade de controle na pesquisa, a depreciação das benfeitorias integrará diretamente como uma despesa no Demonstrativo de Resultado e não ao custo de produção.

\subsection{Cálculo do custo da pastagem}

A pastagem é plantada em uma área total de 130 hectares e os custos de insumos para manutenção e replantio ocorrem 2 (duas) vezes ao ano. A exaustão da pastagem não foi levada em consideração porque é mantida apenas com custos de manutenção e replantio. Assim, a tabela 9 demonstra o cálculo do custo dos insumos utilizados na manutenção e replantio da cultura (pastagem). 
Tabela 9 - Cálculo dos insumos utilizados na manutenção e replantio da pastagem.

\begin{tabular}{lccr}
\hline \multicolumn{1}{c}{ Insumos } & Quantidade & Valor unitário & \multicolumn{1}{c}{ Total } \\
\hline Adubo & 260 sacas & $\mathrm{R} \$ 65,07$ & $\mathrm{R} \$ 16.918,20$ \\
Semente & 20 sacas & $\mathrm{R} \$ 30,00$ & $\mathrm{R} \$ 600,00$ \\
Uréia & 260 sacas & $\mathrm{R} \$ 68,36$ & $\mathrm{R} \$ 17.773,60$ \\
\hline
\end{tabular}

Fonte: dados da pesquisa.

Verifica-se, na tabela 9, que, para replantio e manutenção dos 130 hectares da cultura (pastagem), o empresário rural incorre com $R \$ 16.918,20$ de adubo, $\mathrm{R} \$ 600,00$ de semente e $17.773,60$ de ureia.

Destaca-se que, na manutenção e replantio da pastagem, é utilizado o trator da propriedade para espalhar os insumos e replantios de sementes. Pela falta de controle na propriedade, foi feita uma suposição média da quantidade de sacas de semente que seria utilizada nos replantios da pastagem. Assim, a tabela 10 mostra o cálculo hora máquina utilizada na manutenção e replantio da cultura (pastagem).

Tabela 10 - Cálculo hora máquina utilizada na manutenção e replantio da pastagem.

\begin{tabular}{ccccccc}
\hline Máquina & Horas & Litros & $\begin{array}{c}\text { Valor } \\
\text { diesel }\end{array}$ & Dias & Depreciação & Total $(\mathbf{R} \$)$ \\
\hline Trator & 12 & $5 \mathrm{l} / \mathrm{h}$ & $\mathrm{R} \$ 1,53$ & 5 & $\mathrm{R} \$ 2.105,26$ & $2.472,46$
\end{tabular}

Fonte: dados da pesquisa.

Verifica-se, na tabela 10, que o empresário rural possui um custo de hora máquina que inclui depreciação e combustível do trator em um valor total de $\mathrm{R} \$ 2.472,46$. Por fim, com $\mathrm{o}$ cálculo dos insumos utilizados na manutenção e replantio da cultura (tabela 9), o cálculo da hora máquina utilizada na manutenção e replantio da cultura (tabela 10) e a média de sacas de sementes utilizadas para replantio foi possível calcular o custo total da cultura pastagem. Assim, a tabela 11 apresenta o custo total da cultura (pastagem).

Tabela 11 - Custo total da pastagem.

\begin{tabular}{ccccc}
\hline $\begin{array}{c}\text { Custo } \\
\text { Insumos }\end{array}$ & $\begin{array}{c}\text { Custo hora } \\
\text { máquina }\end{array}$ & Total (R\$) & $\begin{array}{c}\text { Custo Anual do } \\
\text { Gado de corte }\end{array}$ & $\begin{array}{c}\text { Custo dia do } \\
\text { Gado de Corte }\end{array}$ \\
\hline $\mathrm{R} \$ 70.583,60$ & $\mathrm{R} \$ 2.472,46$ & $\mathbf{7 3 . 0 5 6 , 0 6}$ & $\mathrm{R} \$ 284,26$ & $\mathrm{R} \$ 0,7788$ \\
\hline
\end{tabular}

Fonte: dados da pesquisa.

Observa-se, na tabela 11 , que o custo total de insumos foi de $\mathrm{R} \$ 70.583,60$ para as duas manutenções e replantios no ano em estudos. O custo hora máquina foi de $R \$ 2.472,46$, totalizando um custo total da cultura (pastagem) para o exercício social no valor de $\mathrm{R} \$ 73.056,06$.

\subsection{Cálculo da engorda do gado de corte}

Para o cálculo da engorda do gado de corte foram utilizados os valores da mesma época do plantio, ou seja, setembro de 2010. Após muita pesquisa, os valores de engorda animal/dia foram alocados por média de engorda conforme 
Embrapa (2013). Assim, a integração dos custos foi dividida em 4 (quatro) etapas, sendo a primeira do nascimento até $150 \mathrm{~kg}$; a segunda de $151 \mathrm{~kg}$ até $217 \mathrm{~kg}$ (1 ano); e a terceira de $218 \mathrm{~kg}$ até $333 \mathrm{~kg}$; a $4^{\circ}$ de $334 \mathrm{~kg}$ até $400 \mathrm{~kg}$ (2 anos).

Dessa forma, a propriedade rural trabalha com essa média para o crescimento e comercialização do gado de corte. Portanto, se um animal nasce hoje, ele demora aproximadamente 2 anos para engordar e estar pronto para o abate.

Ressalta-se que a propriedade não possui capacidade para reproduzir o número de bezerros necessários para satisfazer sua capacidade de comercialização. Desse modo, algumas vezes há necessidade de comprar bezerros de outras propriedades pagando-se o preço de mercado. Por esse motivo, para facilitar o controle de custo, diferenciaram-se as etapas dos bezerros bem como os anos de engorda. Assim, os custos de cada etapa de engorda foram demonstrados nos itens abaixo.

\section{$4.41^{\circ}$ Etapa do nascimento do bezerro até $150 \mathrm{~kg}$}

Ao nascer, o bezerro é levado a uma espécie de cocheiro onde fica por aproximadamente 60 dias para a formação do seu estômago. Nessa fase, o bezerro ainda não está complemente formado, não conseguindo ingerir a vegetação, ou seja, ingere apenas o leite tirado da sua mãe.

Portanto, os custos alocados a essa etapa são alimentação da matriz (uma vez que fornece o leite para o bezerro) e os medicamentos veterinários. Todos os cálculos demonstrados estão baseados em um crescimento normal, ou seja, sem nenhuma complicação.

Foi levado em consideração que a matriz que fornece o leite ao bezerro consome em médio $15 \mathrm{~kg}$ de silagem/dia que será integralizado ao custo correspondente a essa etapa. Após essa engorda, a matriz fica alimentando-se na pastagem juntamente com o restante do plantel. A tabela 12 mostra o cálculo do custo de bezerro até 60 dias.

Tabela 12 - Cálculo bezerro até 60 dias.

\begin{tabular}{ccc}
\hline Matriz & Vacinas & Total \\
\hline $\mathrm{R} \$ 36,18$ & $\mathrm{R} \$ 5,55$ & $\mathrm{R} \$ 41,73$ \\
\hline
\end{tabular}

Fonte: dados da pesquisa.

Verifica-se, na tabela 12, que o cálculo se refere ao custo de um bezerro normal com até 60 dias. Desse modo, o custo que foi alocado é com a alimentação da matriz e com despesas com vacinação, totalizando 41,73 por bezerro. As vacinas utilizadas são: carbúnculo, IBR, BVD, leptospirose, desverminação e clostridiose. Destaca-se que a vacina para desverminação é a única que precisa ser aplicada duas vezes ao ano, as demais são aplicadas anualmente.

Após 60 dias do nascimento, o bezerro já consegue alimentar-se. Assim, além do leite, alimenta-se de pastagem e de ração própria para crescimento. Então, após esses dias de confinamento, o cálculo do bezerro diferencia-se. Para chegar aproximadamente a $150 \mathrm{~kg}$ são necessários mais 133 dias. Desse modo, o cálculo dos custos do bezerro com até 133 dias está detalhado na tabela 13 .

Tabela 13 - Cálculo bezerro até 133 dias.

\begin{tabular}{cccc}
\hline Ração & Pastagem & Matriz & Total \\
\hline $\mathrm{R} \$ 51,55$ & $\mathrm{R} \$ 90,27$ & $\mathrm{R} \$ 80,20$ & $\mathrm{R} \$ 235,33$ \\
\hline
\end{tabular}

Fonte: dados da pesquisa. 
Para a realização do cálculo apresentado na tabela 13 foi utilizada uma média, ou seja, metade do tempo o bezerro alimenta-se de pastagens e a outra metade de leite fornecido pela matriz. Nessa etapa, a matriz alimenta-se de silagem e de pastagem, diminuído o custo do bezerro. Nesse ponto, o custo do bezerro foi equivalente a $R \$ 235,33$.

Adquirido o peso ideal, o bezerro é destinado aos piquetes onde irá se alimentar de pastagens. Para fechar o primeiro ano de engorda ainda resta um período de 172 dias que será detalhado na próxima segunda etapa.

\section{$4.52^{\circ}$ Etapa de $151 \mathrm{~kg}$ até $217 \mathrm{~kg}$}

Para a realização desse cálculo, foi levada em consideração uma engorda de $0,385 \mathrm{~g} / \mathrm{dia}$, conforme pesquisa em sites especializados. Nessa etapa ainda é aplicada a segunda dose de vacina para desverminação do gado. O gado, nessa etapa de crescimento, alimenta-se de pastagem, silagem e sal mineral, conforme apresentado na tabela 14 .

Tabela 14 - Cálculo dos custos com novilho magro até 172 dias.

\begin{tabular}{ccccc}
\hline Pastagem & Silagem & Sal Mineral & Vacina & Total \\
\hline $\mathrm{R} \$ 66,98$ & $\mathrm{R} \$ 34,57$ & $\mathrm{R} \$ 30,96$ & $\mathrm{R} \$ 1,36$ & $\mathrm{R} \$ 133,87$ \\
\hline Fonte: dados da pesquisa. & & &
\end{tabular}

Para fazer o rateio da alimentação bovina foram adotados os seguintes critérios: a) nos 172 dias foi trabalhado com média, ou seja, 86 dias o novilho foi alimentando com pastagens e 86 dias o novilho foi alimentado com silagem. A alimentação foi divida porque, em períodos de chuvas intensas ou de seca, o novilho é alimentado apenas com silagem e com uma quantidade média de $10 \mathrm{~kg} / \mathrm{dia}$, os outros 86 dias de alimentação com pastagens são integralizados no preço; b) o novilho come aproximadamente $100 \mathrm{~g} /$ dia de sal mineral durante todos os 172 dias; c) e a última dose de vacina ano correspondente à vacina para desverminação.

Assim, no primeiro ano o custo total (desde o nascimento do bezerro até um ano) foi de aproximadamente $R \$ 410,93$ por bezerro. O segundo ano refere-se a terceira etapa de engorda do gado de corte e foram adotados os mesmos critérios da segunda etapa.

\subsection{3ํ Etapa de $218 \mathrm{~kg}$ até $333 \mathrm{~kg}$}

Nessa etapa, os custos alocados para alimentação do gado foram com alimentação de pastagens, silagem e vacinas. Para separação dos custos de cada alimentação, foi adotado um critério de média. Para atingir o peso ideal, o gado precisa engordar 0,385 g/dia em um período de 305 dias, conforme demonstrado na tabela15. 
Tabela 15 - Cálculo dos custos com novilho até 305 dias.

\begin{tabular}{ccccc}
\hline Pastagem & Silagem & Sal Mineral & Vacinas & Total \\
\hline$R \$ 119,160$ & $R \$ 92,26$ & $R \$ 54,90$ & $R \$ 10,19$ & $R \$ 276,51$ \\
\hline
\end{tabular}

Fonte: dados da pesquisa.

Nos 305 dias, para que o gado chegue ao peso ideal, sua alimentação é igual a da segunda etapa. Assim, os 305 dias são divididos por 2 (dois), obtendo-se aproximadamente 153 dias para cada tipo de alimentação. Isso foi feito porque há períodos de escassez de chuva, excesso de chuva e outras adversidades. Portanto, o cálculo foi realizado de acordo com os seguintes critérios: a) para a pastagem, levou-se em consideração o custo multiplicado por 153 dias; b) para a silagem, levou-se em consideração que cada gado se alimenta de aproximadamente $15 \mathrm{~kg}$ de silagem/dia por um período de 153 dias. Assim, em metade do tempo (153 dias), o gado se alimenta da silagem e a outra metade (153 dias) se alimenta de pastagens. Por fim, após a terceira etapa vem a quarta etapa (última) que se refere à engorda em um sistema de semiconfinamento.

\section{$4.74^{\circ}$ Etapa de $334 \mathrm{~kg}$ até $400 \mathrm{~kg}$ - venda}

Esta é a última etapa de engorda do gado que é alimentado com ração especial, sal mineral, pastagem e silagem. Nesse período, o objetivo é aumentar de forma rápida o ganho de peso do animal, ou seja, aproximadamente $0,975 \mathrm{~kg} / \mathrm{dia}$. A tabela 16 apresenta os custos com alimentação para engorda do gado.

Tabela 16 - Cálculo dos custos com gado até 60 dias.

\begin{tabular}{ccccc}
\hline Pastagem & Ração & Sal Mineral & Silagem & Total \\
\hline $\mathrm{R} \$ 46,73$ & $\mathrm{R} \$ 55,56$ & $\mathrm{R} \$ 10,80$ & $\mathrm{R} \$ 48,24$ & $\mathrm{R} \$ 161,33$ \\
\hline
\end{tabular}

Fonte: dados da pesquisa.

Nessa última etapa de engorda, o objetivo é ganhar o máximo de peso para a obtenção de maiores lucros. Assim, para chegar aos custos apresentados na tabela 16, foi realizado o cálculo levando em consideração que, ao longo dos 60 dias, o gado comeria aproximadamente $20 \mathrm{~kg} / \mathrm{silagem}$ dia, $1,5 \mathrm{~kg}$ de ração (que é composta de milho - produzido pela propriedade, mais trigo e farelo de soja). A propriedade apenas tem gasto do trigo e soja pois o milho que integrará a ração é produzido pela própria fazenda e, por fim, o consumo diário de sal mineral. Ao fim do processo, o custo histórico de um gado gordo é de $R \$ 848,77$. A partir desse levantamento de custo histórico haverá a demonstração do Resultado.

\subsection{Demonstração do resultado do exercício}

Com base no levantamento dos custos da atividade, será elaborada a Demonstração do resultado do exercício (DRE) referente ao ano de 2012. Para a obtenção da receita bruta com a venda do gado, foi levada em consideração uma venda aproximada de 12 cabeças de gado/mês e 144 cabeças de gado/ano.

Os animais vendidos são negociados com os compradores com a condição de que o comprador se responsabiliza pelas despesas com frente. Os custos de produção e os impostos referente à operação (Funrural com alíquota de $2,3 \%$ ) são de responsabilidade do produtor.

Para integrar a DRE, também são calculadas as depreciações das benfeitorias, máquinas e equipamentos. Só foram calculadas as depreciações do 
arado, ensiladeira e plantadeira porque o trator já foi depreciado como parte do custo de produção do gado de corte.

A depreciação dos touros e das matrizes não foi levada em consideração na formação do custo de produção do bezerro pela falta de controle adequado na propriedade em estudo. Assim, a depreciação dos touros e das matrizes foi rateada entre todo o plantel. A tabela 17 mostram os cálculos de depreciação.

Tabela 17 - Depreciações dos ativos.

\begin{tabular}{lrrrr}
\hline Item & $\begin{array}{c}\text { Valor } \\
\text { contábil (R\$) }\end{array}$ & $\begin{array}{c}\text { Valor residual } \\
\text { (R\$) }\end{array}$ & $\begin{array}{c}\text { Taxa de } \\
\text { depreciação }\end{array}$ & \multicolumn{1}{c}{ Total } \\
\hline Matrizes & $93.500,00$ & $(55.000,00)$ & $12,5 \%$ & $\mathrm{R} \$ 4.812,50$ \\
Touros & $5.086,00$ & $(1.288,00)$ & $12,5 \%$ & $\mathrm{R} \$ 474,75$ \\
Casa & & $3.000,00$ & $6,67 \%$ & $\mathrm{R} \$ 200,10$ \\
Cerca & & $20.000,00$ & $10 \%$ & $\mathrm{R} \$ 2.000,00$ \\
Cocheira & & $2.000,00$ & $10 \%$ & $\mathrm{R} \$ 200,00$ \\
Galpão & & $2.000,00$ & $6,67 \%$ & $\mathrm{R} \$ 133,40$ \\
\hline Item & Valor & Valor residual & Taxa de & Total \\
& contábil & & depreciação & \\
\hline Arado & & $4.000,00$ & $6,67 \%$ & $\mathrm{R} \$ 266,80$ \\
Ensiladeira & & $12.000,00$ & $14,28 \%$ & $\mathrm{R} \$ 1.713,60$ \\
Plantadeira & & $7.000,00$ & $6,67 \%$ & $\mathrm{R} \$ 466,90$ \\
\hline
\end{tabular}

Fonte: dados da pesquisa.

Deste modo, com os valores das depreciações e com a média de venda de 144 animais por ano, com os custos de produção foi possível apresentar a DRE do exercício 2012. Destaca-se que foram respeitadas as normas estabelecidas pelo CPC 29 e o estoque foi avaliado pelo valor de mercado utilizando as seguintes informações: a) para o ano de 2012, o valor de mercado é de $\mathrm{R} \$ 3,40 / \mathrm{kg}$ (gado); para o cálculo da receita, é adotado o peso de $375 \mathrm{~kg} /$ animal. Assim, a Demonstração de resultado do exercício está descrita na tabela 18.

\section{Tabela 18 - Demonstração de resultado do exercício (DRE) no ano de 2012.} 2012

\section{Receita com venda}

(-) Funrural

(-) Custo dos produtos vendidos

= Lucro bruto do período

(-) Despesa operacional

$(-)$ Luz

(-) Mão de obra

(-) Depreciações

= Resultado do exercício

(+) Ganho com ativo biológico

= Resultado do exercício
$\mathrm{R} \$ 183.600,00$

$(\mathrm{R} \$ 4.222,80)$

$(\mathrm{R} \$ 122.222,88)$

$\mathrm{R} \$ 57.154,32$

$(\mathrm{R} \$ 26.388,05)$

$(\mathrm{R} \$ 720,00)$

$(\mathrm{R} \$ 15.400,00)$

$(\mathrm{R} \$ 10.268,05)$

$\mathrm{R} \$ 30.766,27$

$\mathrm{R} \$ 76.362,40$

$\mathrm{R} \$ 102.513,73$

Fonte: dados da pesquisa.

\subsection{Balanço patrimonial}

Para a análise do balanço patrimonial, foi feito um levantamento dos valores do estoque baseando-se no custo histórico. A avaliação das máquinas e benfeitorias foi feita pelo proprietário da fazenda. A avaliação do balanço de 2012 será feita pelo valor de mercado conforme CPC 29, obtendo-se, assim, a atualização do estoque. 
O valor de mercado pode distorcer a informação, principalmente na hora da avaliar os estoques. O estoque da propriedade foi avaliado pelo custo histórico, chegando a um preço final de custo $\mathrm{R} \$ 848,77$ para um gado gordo, pesando aproximadamente $375 \mathrm{~kg}$. No fechamento do BP, em julho de 2012, o valor do $\mathrm{Kg}$ do gado era de $\mathrm{R} \$ 3,40$. É interessante destacar que, para não proporcionar um "lucro indevido" ou um ganho absurdo com o estoque, o custo histórico serviu para ter um parâmetro no primeiro momento da avaliação. Segue o modelo de BP conforme tabela 19: 
Tabela 19 - Balanço patrimonial entre os anos 2011 e 2012 (valores em R\$).

\begin{tabular}{lrr}
\hline & \multicolumn{1}{c}{$\mathbf{2 0 1 1}$} & \multicolumn{1}{c}{$\mathbf{2 0 1 2}$} \\
\hline 1 Ativo & $\mathbf{1 . 7 1 0 . 7 8 4 , 9 8}$ & $\mathbf{1 . 8 1 3 . 2 9 8 , 7 1}$ \\
1.1 Ativo Circulante & $\mathbf{1 1 0 . 8 7 5 , 0 3}$ & $\mathbf{2 2 8 . 6 5 6 , 8 1}$ \\
1.1.1 Disponível & $\mathbf{3 0 . 0 0 0 , 0 0}$ & $\mathbf{5 8 . 9 7 9 , 8 1}$ \\
1.1.1.1 Banco & $30.000,00$ & $58.979,81$ \\
$\mathbf{1 . 1 . 2}$ Estoques de semoventes & $\mathbf{9 3 . 3 1 4 , 6 0}$ & $\mathbf{1 6 9 . 6 7 7 , 0 0}$ \\
1.1.2.1. Bezerro até 150 Kg & $3.752,00$ & $11.305,00$ \\
1.1.2.1. Novilho de 151 kg até 334 kg & $52.157,10$ & $94.622,00$ \\
1.1.2.1. Novilho acima de 334 Kg & $38.405,50$ & $63.750,00$ \\
1.4 Ativo Não Circulante & $\mathbf{1 . 5 9 9 . 9 0 9 , 9 5}$ & $\mathbf{1 . 5 8 4 . 6 4 1 , 9 0}$ \\
1.4.1 Imobilizado & $\mathbf{1 . 5 9 9 . 9 0 9 , 9 5}$ & $\mathbf{1 . 5 8 4 . 6 4 1 , 9 0}$ \\
1.4.1.1 Terras & $\mathbf{3 4 5 . 9 1 2 , 0 0}$ & $\mathbf{3 4 5 . 9 1 2 , 0 0}$ \\
1.4.1.1.1 Áreas de reservas naturais & $263.552,00$ & $263.552,00$ \\
1.4.1.1.2 Áreas utilizadas para pecuária & $82.360,00$ & $82.360,00$ \\
$\mathbf{1 . 4 . 2}$ Pastagens naturais melhoradas & $\mathbf{1 . 0 7 0 . 6 8 0 , 0 0}$ & $\mathbf{1 . 0 7 0 . 6 8 0 , 0 0}$ \\
1.4.3 Instalações para pecuária & $\mathbf{2 4 . 4 6 6 , 5 0}$ & $\mathbf{2 1 . 9 3 3 , 0 0}$ \\
1.4.3.1 Casa & $3.000,00$ & $3.000,00$ \\
1.4.3.2 Cercas de Arame & $20.000,00$ & $20.000,00$ \\
1.4.3.3 Cocheira & $2.000,00$ & $2.000,00$ \\
1.4.3.4 Galpão & $2.000,00$ & $2.000,00$ \\
1.4.3.5( - ) Depreciação acumulada & $(2.533,50)$ & $(5.067,00)$ \\
1.4.4 Máquinas & $\mathbf{4 5 . 0 0 0 , 0 0}$ & $\mathbf{4 0 . 0 0 0 , 0 0}$ \\
1.4.4.1 Tratores & $50.000,00$ & $50.000,00$ \\
1.4.4.2 (-) Depreciação acumulada & $(5.000,00)$ & $(10.000,00)$ \\
1.4.5 Equipamentos e ferramentas & $\mathbf{2 0 . 5 5 2 , 7 0}$ & $\mathbf{1 8 . 1 0 5 , 4 0}$ \\
1.4.5.1 Arado & $4.000,00$ & $4.000,00$ \\
1.4.5.2 Ensiladeira & $12.000,00$ & $12.000,00$ \\
1.4.5.3 Plantadeira & $7.000,00$ & $7.000,00$ \\
1.4.5.4 (-) Depreciação acumulada & $(2.447,30)$ & $(4.954,60)$ \\
1.4.6 Rebanho Permanente & $\mathbf{9 3 . 2 9 8 , 7 5}$ & $\mathbf{8 8 . 0 1 1 , 5 0}$ \\
1.4.6.1 Matrizes & $93.500,00$ & $93.500,00$ \\
1.4.6.2 Reprodutores & $5.086,00$ & $5.086,00$ \\
1.4.6.3 (-) Depreciação acumulada & $(5.287,25)$ & $(10.574,50)$ \\
2 Passivo & - & - \\
2.1 Passivo Circulante & - & - \\
2.2 Passivo Não Circulante & - & - \\
3 Patrimônio Líquido & $\mathbf{1 . 7 1 0 . 7 8 4 , 9 8}$ & $\mathbf{1 . 8 1 3 . 2 9 8 , 7 1}$ \\
3.1 Capital Social & $\mathbf{1 . 7 1 0 . 7 8 4 , 9 8}$ & $\mathbf{1 . 7 1 0 . 7 8 4 , 9 8}$ \\
3.2 Lucro do exercício & - & $\mathbf{1 0 2 . 5 1 3 , 7 3}$ \\
\hline
\end{tabular}

Fonte: dados da pesquisa.

Foi levado em consideração que a propriedade não comprou nenhum ativo, entre os anos de 2011 e 2012, apenas foi feita uma avaliação e depreciação. O BP é uma importante demonstração, pois apresenta a real situação patrimonial e financeira da empresa.

O BP serve para prestar informações para outras entidades como instituições financeiras, usuários externos e sócios e também para o proprietário ter uma análise de seus bens para tomadas de decisões. Por meio do BP, é possível obter outros indicadores para analisar a atividade como os índices de rentabilidade. 


\section{CONCLUSÕES E RECOMENDAÇÕES}

Conclui-se que a atividade de gado de corte gerou no ano de 2012 um resultado financeiro de $R \$ 30.766,27$, representando uma lucratividade de $16,76 \%$ para a propriedade rural em estudo. Contudo, a adoção das normas internacionais de contabilidade, pela aplicação do CPC-29 "Ativos Biológicos", considera que nas atividades rurais é preciso determinar os ganhos ou perdas decorrentes dos aspectos naturais, e sua não utilização pode afetar de consideravelmente a decisão dos gestores rurais. As conclusões remetem que com a aplicação dos critérios e métodos estabelecidos pelo CPC 29, a propriedade rural obteve um ganho com ativo biológico no ano de 2012 no valor de $\mathrm{R} \$ 76.362,40$, passando a apresentar um lucro no valor de $R \$ 102.513,73$.

A visão obtida pelo estudo de caso mostra que a contabilidade rural é difícil de ser implementada, e os fatores que influenciam negativamente no processo estão relacionados ao desconhecimento do proprietário rural sobre os aspectos informacionais e de controle contábil, e pela falta de recursos que promovam o efetivo controle das movimentações econômico e financeiras da propriedade.

É relevante salientar que a adoção das normas internacionais de contabilidade, pelos critérios propostos no CPC-29 "Ativos Biológicos", o qual trata de regras específicas para as atividades rurais, torna mais complexa a implentação e utilização dos informativos contábeis por parte dos propriedades de fazendas. Além disso, a não utilização dos critérios estabelecidos pelo CPC-29 pode causar distorções relevantes na percepção de lucratividade do negócio rural, tornando-se um fator considerável para o proprietário rural. Assim, é preciso dedicação por parte parte dos profissionais para que a contabilidade rural tome proporções e tenha seu devido reconhecimento.

Para estudos futuros, recomenda-se o levantamento detalhado dos custos, com a finalidade de alavancar a produção, e oferecer ao empresário rural uma melhor compressão sobre a real situação econômica, financeira e patrimonial da fazenda. O fato é relevante pela pouca utilização dos relatórios e controles gerados pela contabilidade para administrar as posses em propriedades rurais.

\section{REFERÊNCIAS}

BORILLI, S. P.; PHILIPPSEN, R. B.; RIBEIRO, R. G.; HOFER, E. O uso da contabilidade rural como uma ferramenta gerencial: um estudo de caso dos produtos rurais no Município de Toledo - PR. Revista Ciências Empresariais da UNIPAR, Toledo, v.6, n.1, jan./jun., 2005.

BORNIA, Antonio Cezar Análise Gerencial de Custos: Aplicação em empresas modernas. São Paulo: Atlas, 2010.

BRUNI, A. L.; FAMÁ, R. Gestão de custos e formação de preços: - com aplicação na calculadora HP 12 C e Excel. 5 ${ }^{\underline{a}}$ ed. São Paulo: Editora Atlas S.A., 2011.

CALLADO, A. L. C.; ALMEIDA, M. A. Perfil dos artigos sobre custos no agronegócio publicados nos anais do Congresso Brasileiro de Custos. Revista Custos e Agronegócio on line, v. 1, n. 1 - Jan/Jun - 2005.

CALDERELLI, A. Enciclopédia contábil e comercial brasileira. 30ª ed. São Paulo: CETEC, 1997. 
COMITÉ DE PRONUNCIAMENTOS CONTÁBEIS. Ativo Biológico e Produto Agrícola - CPC 29. Disponível em: <http://www.cpc.org.br/pdf/CPC_29.pdf>Acesso em: 25 set. 2012.

COSTA, M. S. D.; LIBONATI, J. J.; RODRIGUES, R. N. Conhecimentos sobre particularidades da contabilidade rural: um estudo exploratório com contadores da região metropolitana de Recife. Revista ConTexto, Porto Alegre, v. 4, n. 7, 2004.

CREPALDI, S. A. Contabilidade rural: uma abordagem decisorial. 6 ${ }^{\mathbf{a}}$ ed. revista, atualizada e ampliada. São Paulo: Editora Atlas S.A., 2011.

EMBRAPA. Empresa Brasileira de Pesquisa Agropecuária, 2013. Disponível em: <http://www.cpao.embrapa.br/portal/artigos/artigos/artigo7.html>. Acesso em: 05 out. 2013.

HOFER, E.; BORILLI, S. P.; PHILIPIPSEN, R. B. Contabilidade como ferramenta gerencial para atividade rural: um estudo de caso. Revista Enfoque: Reflexão Contábil. v.25, n. 3, 2006.

MAGRO, C. B. D.; DOMENICO, D. D.; KLANN, R. C; ZANIN, A. Contabilidade rural: comparativo na rentabilidade das atividades leiteira e avícola. Revista Custos e Agronegócio on line, v. 9, n. 1 - Jan/Mar - 2013.

MARION, J. C. Contabilidade Rural: contabilidade agrícola, contabilidade pecuária, imposto de renda- pessoa jurídica. 13 ed. São Paulo: Atlas, 2012.

NEVES, S. D.; VICECONTI, P. E. V. Contabilidade de custos: um enfoque direto e objetivo. 6 ed. revisada e ampliada. São Paulo: Frase Editora, 2000.

PADOVEZE, C. L. Curso básico para gerencial de custos. 2. ed. São Paulo: Pioneira Thomson Learning, 2006.

SANTOS, J. D.; MARION, J. C.; SEGATTI, S. Administração de custos na agropecuária. 3 Ed. São Paulo: Editora Atlas S.A., 2002.

VANDERBECK, E. J.; NAGY, C. F. Contabilidade de custos. 11. ed. São Paulo: Pioneira Thomson Learning, 2011.

ZANIN, A.; KRUGER, S. D.; MAZZIONI, S.; DEIMLING, M. F.; DOMENICO, D. D. Gestão ambiental em agroindústrias da região de Chapecó. In: XVII SIMPEP Gestão de Projetos e Engenharia de Produção. São Paulo, 2010. 